Tejidos con 'denominación de origen extranjera' en el vestido castellano. 1500-1860

Austria. Tela con la trama de algodón, usada para forro de vestidos.

Polonesa. Tejido hecho con la trama de algodón, usado para forros. 



\title{
UN EJEMPLO DE RELIGIOSIDAD BARROCA. LA V.O.T. FRANCISCANA DE LA CIUDAD DE LEÓN
}

\author{
Alfredo MARTín GARCÍA \\ Universidad de León
}

\begin{abstract}
RESUMEN: La tercera orden seglar se convirtió en uno de los vehículos más eficaces para la propagación de la reforma tridentina y la espiritualidad franciscana en la Europa barroca. A través del análisis particular del caso leonés, comprobamos su capacidad de mimetismo, así como sus dimensiones económicas, sociales y devocionales.

PALABRAS CLAVE: tercera orden franciscana, mentalidades, religiosidad barroca, historia social, León.

ABSTRACT: Third Lay Order was one of the most effective vehicle to propagate the reform of Trento and Franciscan spiritually in the Baroque Europe. Through the analysis of the León's documentation, we verify its mimesis capacity and its economic, social and devotional dimensions.
\end{abstract}

KEY WORDS: Franciscan Third Order, mentalities, Baroque religiosity, social history, León.

\section{LA REFORMA TRIDENTINA Y EL FRANCISCANISMO SEGLAR ${ }^{1}$}

La Orden Tercera de Penitencia de San Francisco hunde sus raíces en la Europa del siglo XIII ${ }^{2}$, época marcada por la crisis de la Iglesia y, también, por la renovación espiritual que trajeron consigo las órdenes mendicantes, especialmente

${ }^{1}$ Este artículo forma parte del proyecto de investigación titulado "La Orden Tercera Seglar Franciscana en la Península Ibérica durante el Antiguo Régimen", subvencionado por la Fundación Caja Madrid en su convocatoria 2002/2003 de becas postdoctorales. Agradecemos a D. José Luis Blanco, ministro de la Orden Franciscana Seglar de León, las facilidades prestadas para la consulta de la documentación perteneciente a su fraternidad.

${ }^{2}$ A lo largo del artículo emplearemos las siglas V.O.T. (Venerable Orden Tercera de Penitencia del Seráfico Padre San Francisco) para referirnos al movimiento seglar franciscano. Así era conocido en la época y así siguió titulándose hasta bien entrado el siglo XX. Las siglas empleadas en este trabajo son las siguientes: A.V.O.T.L. (Archivo de la Venerable Orden Tercera de León); A.V.O.T.M. (Archivo de la Venerable Orden Tercera de Madrid). 
franciscanos y dominicos. Una de las muestras más evidentes de la influencia mendicante en la sociedad medieval fue el nacimiento de las órdenes terceras, de entre las cuales destacó por encima de todas la franciscana. Si bien Francisco de Asís no fue el creador de este tipo de agrupaciones seglares, sí que se le puede considerar su gran impulsor. Y es que el "poverello" reinventó el movimiento penitencial laico convirtiéndolo en algo nuevo; no porque su programa de vida fuese una absoluta novedad, sino por el hecho relevante de que a partir de ese momento todos los seglares que quisieran vivir comunitariamente los ideales de vida religiosos, no estaban obligados a entrar en una orden regular: tenían a su disposición una plenamente laica, reconocida oficialmente por la Iglesia. Con este reconocimiento, Roma trataba de legalizar un modo de religiosidad preexistente pero que se hallaba no sólo fuera de su ordenamiento sino, incluso, condenado como herético. Fueron pues los terciarios franciscanos los principales responsables de la consolidación y regularización del papel de los seglares en la religiosidad medieval ${ }^{3}$.

Algunos autores sitúan el nacimiento de la V.O.T. en 1221, año del "Memoriale propositi", texto al parecer del cardenal Hugolino aunque directamente inspirado en el pensamiento de Francisco de Asís ${ }^{4}$. Sea como fuere, habrá que esperar hasta 1289 para que se produzca su reconocimiento oficial. Ese año un papa franciscano, Nicolás IV, aprobó su regla, texto legislativo básico que pervivirá hasta los tiempos de León XIII, a finales del siglo XIX ${ }^{5}$. La rapidez con la que el papado respaldó la fórmula de vida franciscana seglar, contrasta con su actitud para con otras organizaciones laicas contemporáneas y refleja el éxito del franciscanismo en la sociedad de la época ${ }^{6}$. Ese firme respaldo favoreció la rápida extensión de la V.O.T. por toda la Europa cristiana, siguiendo los pasos de sus hermanos de la primera orden. Pero tras el esplendor de los siglos XIII y XIV, las dos siguientes

${ }^{3}$ POMPEI, A. (1973). «Il movimento penitenziale nei secoli XII-XIII»". Collectanea franciscana, pp. 9-40, p. 38; GRAÑA, M.M. (1990). «La órdenes mendicantes en el obispado de Mondoñedo. El convento de San Martín de Villaoriente (1374-1500)». Archivos Mindonienses, pp. 13-46, p. 13.

\footnotetext{
${ }^{4}$ Manselli, R. (1997). Vida de San Francisco de Asís. Oñati: Editorial Franciscana Aránzazu, p. 269.

5 Para un conocimiento en profundidad de los orígenes de la tercera orden franciscana a partir de las primeras comunidades de penitenciales, continúan vigentes los trabajos clásicos de Péano o Amberes. Amberes, F. (de) (1925). La Tercera Orden Secular de San Francisco, 1221-1921. Barcelona (1 ${ }^{\text {a }}$ Ed. Roma 1921); PÉANO, A. (1943), Histoire du Tiers Ordre, París.

${ }^{6}$ Los terciarios dominicos tuvieron que esperar hasta 1406 y los servitas a 1424 para obtener el placet de Roma. Manterola, M. (1923). Instituto popularísimo (La Orden Tercera Franciscana). Tomo I. Santiago: El Eco Franciscano, p. 237.
} 
centurias fueron una etapa de franca decadencia para el movimiento. La crisis de la Iglesia bajomedieval y la reforma protestante tuvieron mucho que ver en ese retroceso, a lo que, en el caso específico castellano, hay que añadir el complejo asunto del reformismo franciscano. En consecuencia, a finales del siglo XVI, la orden de penitencia se encontraba en la Corona de Castilla si no desaparecida sí en inminente peligro de extinción.

El cambio de tendencia se produjo a partir de 1606. En ese año y durante el capítulo celebrado en Toledo por la familia cismontana, el comisario general, Fr. Pedro González de Mendoza, ordenó que "la tercera orden que nuestro padre S. Francisco instituyó para los casados y solteros, se publicase y procurase instituir en todas las provincias de Castilla a imitación de lo que en la de Aragón se guarda"?. Estas disposiciones fueron ratificadas en el posterior capítulo toledano de 1609 y en el de Segovia de 1621. Pero no fueron los observantes los únicos franciscanos decididos a la propagación de la V.O.T. Poco después, y no sin ciertos problemas jurídicos, otras ramas de la familia, en especial los capuchinos, se dedicaron con el mismo ardor a la propagación del espíritu seráfico entre los laicos ${ }^{8}$. Esta agresiva política de evangelización de la sociedad seglar, debe encuadrarse en el redescubrimiento del asociacionismo laico que experimentó la Iglesia postridentina, y en donde la V.O.T. desempeñó un papel de primer orden ${ }^{9}$. A través de este vehículo, el seglar participaba activamente en la vida religiosa, obteniendo una serie de privilegios espirituales más que considerables. En contrapartida, la economía conventual se beneficiaba tanto de los ingresos anuales concedidos por la nueva fraternidad como del incremento de su influencia -no sólo desde el punto de vista ideológico- dentro de la sociedad.

${ }^{7}$ El texto parece recalcar las diferencias entre una Corona de Castilla en la que el franciscanismo seglar se encontraba casi desaparecido y una Corona de Aragón en donde, al menos por aquellas fechas, gozaba de mejor salud. CARRILlo, Fr. Juan (1610). Primera parte de la Historia de la Tercera Orden de Nuestro Seraphico P. S. Francisco, Zaragoza: Imprenta de Juan Lanaja y Quartanet, pp. 2728.

${ }^{8}$ Los capuchinos no pudieron fundar conventos en Castilla hasta 1609, fecha en la que Felipe III, tras las hábiles gestiones del P. Serafín de Polizzi y de San Lorenzo de Brindis, levantó la prohibición que había impuesto su padre. Esta circunstancia, unida al posterior proceso de organización de las provincias de Castilla y Andalucía tuvo que significar un retraso en las fundaciones terciarias con respecto a los observantes. AldEA, Q., MARIN, T. y ViVES, J. (dirs.) (1972-1987). Diccionario de Historia eclesiástica de España. Madrid: Instituto Enrique Florez, Consejo Superior de Investigaciones Científicas, Vol. I, p. 340.

9 REY, O. (1999). «La orden tercera franciscana en el contexto del asociacionismo religioso gallego en el Antiguo Régimen: La V.O.T. de la villa de Padrón». Archivo Ibero-americano, pp. 3-47, p. 3. 
El respaldo de los frailes menores fue pues capital para el desarrollo de la tercera orden. Los religiosos no se contentaron únicamente con extender aquel instituto por todo el orbe católico o dirigir espiritualmente las nuevas fraternidades. También ofrecieron una cobertura legal que, en muchas ocasiones, resultó determinante en la batalla por la autonomía que tuvieron que afrontar los terciarios frente a la jurisdicción diocesana ${ }^{10}$. No deja de resultar tremendamente significativo al respecto la ubicación de las capillas de la V.O.T. casi siempre contiguas al convento franciscano de turno para, de esta manera, gozar del parapeto legal que constituía la inmunidad de aquel terreno. Así lo hicieron, sin ir más lejos, los propios terciarios de la ciudad de León. Además, el buen hacer de los frailes de la primera orden y su influencia entre las clases dirigentes de la sociedad o en la propia corte, contribuyó de manera efectiva a la extensión del movimiento. La monarquía católica durante el siglo XVII se contagió de este clima de franciscanismo, favoreciendo de manera notable la difusión del modo de vida terciario. Esta actitud de los Austrias está en clara sintonía con el comportamiento de los Saboya o los Gonzaga en sus territorios patrimoniales durante esa misma época $^{11}$. En consecuencia, la V.O.T. se extendió de manera imparable por toda la Corona de Castilla en el XVII, acudiendo a tomar el hábito de San Francisco no sólo los miembros más selectos de la sociedad, sino también las clases populares. Desde el punto de vista geográfico, ese "furor terciario" tuvo como epicentro el entorno de Toledo y Madrid, en donde ya se constata la fundación de fraternidades en la primera década del siglo ${ }^{12}$. Desde allí se fue extendiendo hacia todas

\footnotetext{
${ }^{10}$ Aunque a lo largo del Antiguo Régimen fueron numerosas las tensiones entre los terciarios y las autoridades parroquiales, no es menos cierto que muchos obispos se erigieron en destacados defensores de la propagación de la V.O.T. y que un amplio sector del clero secular apoyó decididamente la creación y desarrollo de hermandades de la tercera orden, participando activamente en la vida terciaria.

${ }^{11}$ Los tres reyes de aquella centuria -Felipe III, Felipe IV y Carlos II- tomaron el hábito franciscano, gesto que constituyó un fenomenal vehículo de propaganda para la V.O.T. SERRA, V. (1997). «Els terciaris a Catalunya durant els segles XVII i XVIII». Analecta Sacra Tarraconensia, pp. 119-188, p. 121; Diaz De San Buenaventura, Fr. Francisco (1683). Primera parte del espejo seráfico, destierro de ignorancias y antorcha contra las últimas dudas que descubrió el discurso: Sacada a vista del mundo para los insignes penitentes hijos de la esclarecida, siempre venerada y no menos que Seráfica Orden Tercera del Serafin llagado de la Iglesia nuestro Glorioso P. y Patriarca San Francisco. Santiago: por Antonio Fraiz, p. 216.

${ }^{12}$ Los franciscanos aprovecharon la celebración de su capítulo toledano de 1606 para predicar el estatuto de la V.O.T. en la ciudad, "y fue tan notable el efecto que hizo la predicacion del en todos los estados (assi de ecclesiasticos que viven en sus casas como de seglares) que en muy pocos días, fue cosa notable ver la devocion entrañable, con que muchas personas principales de los dichos estados (y
} 
direcciones, alcanzando los territorios periféricos de la Corona en el último tercio de la centuria o las primeras décadas del siglo XVIII.

\section{¿COFRADES O INTEGRANTES DE UNA ORDEN?}

Durante la Edad Moderna, los terciarios franciscanos se mostraban orgullosos de pertenecer a algo más que a una mera cofradía. Desde el punto de vista formal, la V.O.T. era una orden religiosa, con regla aprobada por Roma y una serie de privilegios espirituales muy superiores a los de cualquier otra agrupación seglar. Sus postulantes, para poder recibir el hábito, debían pasar un examen de doctrina cristiana, así como demostrar su limpieza de sangre y buenas costumbres. Además, debido a su carácter de orden, era absolutamente necesario superar un año de noviciado para poder formar parte, como miembros de pleno derecho, de la fraternidad. Una vez franqueado ese período de prueba y si su edad y estado lo permitían $^{13}$, se celebraba en la capilla de la V.O.T. la ceremonia de profesión, presidida por sus dos máximas autoridades: el padre visitador y el hermano ministro. Para ello, era necesario cursar la pertinente solicitud a la junta de gobierno, como hizo el 20 de noviembre de 1808, un matrimonio de hermanos novicios de la ciudad de León:

“Andrés Carnizero y su muger Jerónima Suarez, vecinos en la parroquial de San Pedro de los Huertos, puesto ante buestras caridades, dicen se allan cumplidos del año de su nobiciado y por tanto suplican a buestras caridades se dignen tener a vien mandar se les de la santa profesion, que en ello reciviran mercez, al mismo tiempo que a Dios pedirá guarde siglos por años sus importantes vidas. "14

Concluida la ceremonia, los nuevos hermanos recibían una patente firmada por el visitador y el ministro, con sello y refrendo del secretario. Este documento era de especial importancia pues acreditaba su pertenencia a la orden. Cuando por el motivo que fuese, el hermano cambiaba de lugar de residencia, podía presentar en la nueva fraternidad su patente, mediante la cual se le recibía como un miembro más. Esta posibilidad de mantener el modo de vida terciario a pesar del cambio de domicilio, constituía una notable diferencia con respecto a las cofradías,

otras muchas que no lo eran tanto) acudían al convento de San Juan de los Reyes de la misma ciudad pidiendo aquel santo habito, con desseos y efectos entrañables de vivir en el y concertar sus vidas, conforme a aquella tan santa y saludable regla". Tres años más tarde se fundaba la fraternidad madrileña. CARrillo, Fr. J., Primera parte de la Historia de la Tercera ..., p. 572; A.V.O.T.M., Libro $1^{o}$ de acuerdos, fols. 1-3.

${ }^{13}$ Era absolutamente necesario tener, al menos, dieciséis años y, en caso de las esposas, contar con la autorización del marido.

${ }^{14}$ A.V.O.T.L., Papeles sueltos. 
circunscritas a un ámbito territorial concreto. La entrada y salida de hermanos marcaba la vida cotidiana de las diferentes fraternidades terciarias, sobre todo de las ubicadas en suelo urbano. La dimensión del movimiento queda reflejado en las enormes distancias que podían separar a la fraternidad de procedencia de la de acogida: en enero de 1771 se incorporó a la V.O.T. leonesa el hermano Joaquín Alonso en virtud de patente firmada en la ciudad de La Habana. Seis años después hacía lo propio Doña Mariana Furió, procedente de la fraternidad de Ceuta ${ }^{15}$. De igual forma, aquellos terciarios que, por azares de la vida, se dedicaban a la mendicidad, obtenían con la presentación de dicho documento, la certeza de la recepción de una limosna, siempre que visitasen por primera vez una hermandad terciaria.

Otro elemento distintivo del carácter de orden de la V.O.T. era el hábito. Desde tiempos medievales se hizo común la utilización por parte de los terciarios de vestimentas parecidas a las de los frailes menores. Durante el siglo XVI y comienzos del XVII, el empleo de esta señal externa había derivado en un intolerable abuso, no sólo por parte de los propios hermanos sino incluso desde sectores ajenos a la orden, que se aprovechaban de él para ganarse la vida. A este respecto, las ordenaciones de Fr. Bernardino de Sena (1626) buscaban una estricta regulación en la concesión de estas vestimentas y la implacable persecución de los falsos terciarios ${ }^{16}$. Existían dos tipos de hábitos: los descubiertos o exteriores y los secretos o interiores. La concesión de los segundos era poco problemática, permitiéndose incluso licencias en cuanto al material que debía emplearse en su confección. Las principales restricciones se pusieron al hábito exterior, al ser el causante de todos los abusos señalados. En primer lugar, se prohibía su empleo hasta después de la profesión y, además, se restringía de manera importante su uso: el portador del hábito externo no sólo tenía que ser hombre o mujer de rectísima conducta cristiana sino que también era recomendable que poseyera el suficiente patrimonio como para no temer que lo pudiese utilizar en provecho propio. A veces esa garantía económica la ofrecía la propia orden, convirtiendo a aquellos hermanos en criados de la fraternidad. Así, al menos durante la segunda mitad del siglo XVIII, los cuatro sirvientes de la V.O.T. leonesa vestían hábito descubierto ${ }^{17}$. Por otro lado, la orden tercera a instancias de Fr. Bernardino, consiguió de Felipe

15 A.V.O.T.L., Libro de entradas de hermanos, fol. 131; Libro de entradas de hermanas, fol. 135.

16 SENA, Fr. Bernardino de (1719). Ordenaciones generales para el mejor, más fácil, claro y suave gobierno espiritual y temporal de la Venerable Orden Tercera de Penitencia, en todos los reinos de España. Santiago, p. 36.

${ }^{17}$ A.V.O.T.L, Libro de enterramientos y de inventario de la V.O.T. de León (1763), fol. 150. 
IV una provisión real -fechada en Madrid, el 17 de agosto de 1628- por la que podía servirse de las autoridades civiles para despojar de su hábito a aquel individuo que lo vistiese sin su consentimiento. Unos años más tarde, Urbano VIII, en la bula de 5 de octubre de 1638 titulada "Ad futuram rei memoriam", incidía de nuevo en el problema, prohibiendo los hábitos sin concesión "in scriptis" de los prelados de la orden y mandando a sus nuncios y ordinarios que "se los quiten irremisiblemente, imponiéndoles las penas que a su arbitrio les parecieren necesario" ${ }^{\prime 18}$.

Poseer un hábito y una regla aprobada por Roma eran dos elementos consustanciales a las órdenes que poseía la V.O.T. Sin embargo, los terciarios ni hacían vida en común, ni emitían votos públicos ${ }^{19}$, diferencias más que notables con respecto a los regulares como para que su posición en la estructura eclesiástica no fuese harto confusa. De hecho, la polémica entre defensores y detractores de su definición como orden fue el pan de cada día durante el período. Incluso hasta sus más vehementes paladines, los frailes menores, no admitían una total equivalencia con las órdenes regulares. La base de la argumentación franciscana se centraba en la siguiente afirmación: la V.O.T. debía denominarse orden por estar aprobada por la Iglesia y conocérsele oficialmente con ese nombre. Sin embargo, debido a sus especiales características, no podía considerarse religión ${ }^{20}$. Por tanto, la confusión pervivió durante todo el período, a pesar de los continuos intentos del papado por perfilar nítidamente su status. Los terciarios tuvieron que defender en muchas ocasiones sus particularidades frente a la abierta oposición de ciertos sectores de la Iglesia. Tradicionalmente, el principal interesado en negar la condición de orden a la V.O.T. fue el clero secular, sobre todo, los párrocos de las localidades en donde se fundaba. Cuando la fraternidad franciscana seglar era lo suficientemente fuerte como para erigir una capilla, el temor a una intromisión en los derechos parroquiales convertía al cura en un enemigo declarado. Otras veces, el cuestionamiento de su status venía de otras asociaciones laicas que se consideraban perjudicadas por aquel monopolio de privilegios. Los conflictos por la posición en un entierro o en una procesión entre los terciarios franciscanos, los dominicos, los

${ }^{18}$ Diaz De San Buenaventura, Fr. F. Primera parte del espejo seráfico..., pp. 211 y 272.

${ }^{19}$ Sobradillo, A.M. (1935). La Tercera Orden de San Francisco según el código de derecho canónico. Santander, pp. 1-2.

${ }^{20}$ Entiéndase el término religión como orden regular. ARBIOL, Fr. Antonio (1714). Los terceros hijos de el Humano Serafín. La Venerable y esclarecida orden tercera de N. Seráfico Patriarca San Francisco, Zaragoza: herederos de Manuel Román, p. 120; CARrillo, Fr. J. Primera parte de la Historia de la Tercera..., p. 586. 
servitas o los cofrades de alguna hermandad especialmente importante, fueron abundantes durante todo el Antiguo Régimen y originaron, en muchas ocasiones, una intensa polémica, traducida en tratados o pequeños folletos, legitimando o desacreditando los privilegios de la V.O.T.

No obstante, los pontífices atendieron, en general, favorablemente las reclamaciones terciarias en las disputas con el clero diocesano $\mathrm{u}$ otras congregaciones laicas. En el primer tercio del siglo XVI, Clemente VII en su bula "Ad fruct. uberes" excomulgaba a los que la denominaran cofradía, congregación "o con otro nombre menos que de orden". Benedicto XIII en la "Ad nostram audientiam" - Roma 21 abril de 1728- le concedía antelación y precedencia "a todas y qualesquiera hermandades y cofradías laycales por ilustres que sean, al modo que las demás órdenes, no obstante qualquier juzgado, sentencia y aún costumbre inmemorial", con pena de excomunión mayor para todos aquellos que quisiesen impedir desarrollar sus gracias, favores, privilegios y exenciones ${ }^{21}$. Por su parte, Benedicto XIV en su Breve "Emanavit nuper" -7 de enero de 1749aprobó y confirmó para toda España, a petición de los terciarios gaditanos, que "procediendo procesionalmente en qualquiera entierro o función eclesiástica, bajo nuestra propia cruz o bajo la de los religiosos de la primera orden", gozaran la precedencia referida. Todos estos privilegios fueron aprobados y corroborados por Clemente XIV en su breve "Pias Christi Fidelium"-Roma 16 de junio de $1773{ }^{22}$.

Ante este importante abanico de prerrogativas, no podemos menos que reconocer que junto al interés por el desarrollo de una religiosidad más intensa, los aspirantes a terciarios podían ver en su ingreso en la V.O.T. una apetecible oportunidad de promoción dentro de una sociedad como aquella tan marcada por el privilegio. Una manifestación evidente de la posición que había adquirido la V.O.T. franciscana a lo largo de los siglos, la encontramos en el propio caso leonés. En las ordenaciones particulares de la fraternidad de 1753, se señalaba que en los entierros de los hermanos "va la tercera orden en dos filas, precediendo a

${ }^{21}$ Aún a comienzos del siglo XX, el derecho canónico señalaba la precedencia de las terceras órdenes en general sobre las demás piadosas asociaciones en las celebraciones religiosas. Asimismo, de entre las diferentes órdenes terceras, la franciscana tenía la precedencia, por ser la más antigua. MANTEROLA, M. Instituto popularísimo..., p. 31.

${ }^{22}$ INDULGENCIAS, gracias y privilegios de la Venerable Orden Tercera de Penitencia de Nuestro Seráfico Padre San Francisco, Santiago 1825, pp. 4-6. 
todas las cofradías" ${ }^{23}$. Más tarde, en junio de 1826, cuando los integrantes de la fraternidad decidieron ganar el jubileo decretado por el papa León XII, acordaron "proponer y suplicar vervalmente al Sr. Governador del obispado, permitiese que en la procesión siguiese al estandarte de la V.O.T. cruz alta y ciriales". La máxima autoridad de la diócesis en aquel momento, no puso ningún reparo a esa petición, recalcando los terciarios que aquella forma de procesionar por las calles leonesas la habían ejecutado "nosotros únicamente y los cavildos de la Santa Iglesia y San Isidro el Real" ${ }^{\prime 24}$.

\section{EL DESARROLLO DEL MODO DE VIDA TERCIARIO EN LEÓN}

Desde el punto de vista estrictamente legal, el documento base de ordenación de la vida terciaria en todo el orbe católico era la regla medieval, aprobada por Nicolás IV en 1289. Sin embargo, las disposiciones nicolasianas eran demasiado abstractas, dejando sin cubrir aspectos cruciales como la propia organización interna de la orden. Además, las fraternidades de la Época Moderna poco o nada tenían que ver con las primeras agrupaciones penitenciales del Medievo. Por esa razón, en la Corona de Castilla, desde comienzos del siglo XVII, los distintos ministros generales de la orden franciscana comenzaron a redactar mandatos y ordenaciones para complementar y aclarar aquellos aspectos más difusos de la regla. Los primeros pasos los dieron Fr. Pedro González de Mendoza en 1606 y Fr. Arcángel de Mesina en $1609^{25}$. No obstante, fueron las ordenaciones de Fr. Bernardino de Sena (1629) las más completas y, por ende, las que dejaron una huella más profunda en la organización y vida cotidiana de las fraternidades terciarias. A partir de 1689, empero, los estatutos generales aprobados por el general de la orden Fr. Pedro Marino Sormano y confirmados por bula especial de Inocencio XI, se convirtieron ya en el ineludible complemento a la regla para las fraternidades de todo el mundo ${ }^{26}$. Cada una de ellas, además, contaba con sus estatutos particulares en los que se adecuaba la regla terciaria a las peculiaridades de la localidad en donde se había erigido. Y es que, como señalaba Fr. Isidro de la Santísima Trinidad:

${ }^{23}$ CAno, Fr. Miguel (1758). Regla de la Tercera Orden de Penitencia, que fundó el Seraphico Padre San Francisco para los seglares de uno y otro sexo y de diversos estados que viven en sus casas. Valladolid, p. 53.

${ }^{24}$ A.V.O.T.L., Libro de acuerdos (1826-1881), fol. 5.

${ }^{25}$ Fray Pedro era comisario general de la familia cismontana. CARRILlo, Fr. J. Primera parte de la Historia ..., pp. 27 y ss.

${ }^{26}$ SERRA, V. «Els terciaris a Catalunya...», p. 126. 
"en esta materia de constituciones y estatutos para el buen govierno de la Orden Tercera, es preciso se ajuste en cada pueblo a lo que alli se puede practicar. Todo lo que se hace en la Tercera Orden de Madrid, no se puede practicar en la de Mexico, ni lo que se practica en la Tercera Orden de Mexico se puede ejecutar en la de Manila",27.

También los terciarios de la ciudad de León contaban con unos estatutos propios, publicados por primera vez a mediados del siglo XVIII y reeditados un siglo más $\operatorname{tarde}^{28}$. En junta de gobierno celebrada el 22 de mayo de 1741 y presidida por el ministro D. Manuel de Soto y el visitador Fr. Luis de Rebolledo y Rojas, éste propuso la conveniencia de contar con un librillo que contuviese la regla, estatutos generales y ceremonial practicado por los terciarios de la ciudad. No se trataba de una idea original sino que se estaba imitando a "las terceras ordenes más principales" y en especial a la de Oviedo que en fechas cercanas había editado una obra semejante. El propio Fr. Manuel se encargó de redactar la obrilla aunque las dificultades económicas que atravesaba la fraternidad por aquellos años, impidieron su pase a imprenta. Hubo que esperar pues hasta 1750 para que se retomase el proyecto. En 26 de diciembre de ese año el discretorio leonés encargó al nuevo visitador Fr. Miguel Cano que la revisase y la pusiese al día. Poco después, "haviendo querido Dios se desempeñase de sus deudas la tercera orden", se publicó por fin la obra ${ }^{29}$.

Regla y estatutos se orientaban hacia la consecución de unos mismos objetivos: lograr que los terciarios se caracterizasen por llevar adelante unas prácticas religiosas más intensas que el resto de los cristianos, siguiendo el modelo de vida de San Francisco de Asís, fundamentado en la penitencia, el espíritu de pobreza y las obras de misericordia. Igualmente, todos los textos reguladores de la vida terciaria incidían en la importancia de poseer un perfecto conocimiento de la doctrina cristiana para acceder a la orden, para lo cual se instituía la obligatoriedad de que el postulante superase un examen de conocimientos en esta materia ${ }^{30}$. Una

${ }^{27}$ SANTísima Trinidad, Fr. Isidro (1745). Jardín seráphico. Sampaloc: convento de N. Sra. de Loreto, pp. 61-62.

${ }^{28}$ Desconocemos el año exacto de la primera impresión, aunque sabemos el lugar-Valladolid- y que las licencias oportunas fueron concedidas en 1753. La reimpresión se realizó en 1854 en la imprenta de Alonso del Riego de la misma ciudad. CANO, Fr. M. Regla de la Tercera Orden de Penitencia...

${ }^{29}$ El visitador no puso objeción alguna al texto de su antecesor. No así algunos hermanos terceros que consideraron necesario actualizar algunos puntos.

${ }^{30}$ REY, O. «La orden tercera franciscana en el contexto...», pp. 9 y ss; SERRA, V. «Els terciaris franciscans a l'epoca moderna ...», p. 97. 
exigencia nueva con respecto a la regla medieval fue la necesidad de demostrar limpieza de sangre: recibida la petición del solicitante, la junta de gobierno ministro y discretos- junto al visitador, pedía a algunos hermanos "información secreta de la limpieza, vida y costumbres" para comprobar si el pretendiente cumplía los requisitos para entrar en ella. La averiguación consistía en comprobar si se trataba de un cristiano viejo - sin sangre mora, judía o hereje- y si poseía un oficio conocido que le sustentase, sin la necesidad de tener que mendigar. Este último punto era de vital importancia, ya que abundaban los aspirantes a terciarios que buscaban en la obtención del hábito un interesante recurso de sostenimiento económico mediante la mendicidad.

El hábito era el distintivo externo más evidente del modo de vida franciscano seglar. Sin embargo, todos los textos normativos otorgaban al comportamiento de los terciarios un valor más importante. En todos los episodios de su vida el hermano de la V.O.T. debía dejarse guiar por los dos valores fundamentales de la orden: la humildad y la pobreza. En la regla de 1289 se insistía en que los terciarios no asistiesen ni a convites, ni a bailes ni a juegos. Asimismo, se abogaba por la moderación en las comidas $^{31}$ : la abstinencia de comer carne era una de las principales exigencias. Aquellos hermanos sanos -los enfermos estaban exentosno debían ingerirla ningún lunes, miércoles, viernes y sábados del año, excepción hecha de las grandes festividades del calendario litúrgico. Además, todos los viernes era obligatorio el ayuno. En las disposiciones nicolasianas incluso se prohibía portar armas "si no fuera por defensa de la Iglesia Romana y de la Fe de Christo o por defenderla de su patria o de licencia de sus ministros". Sin embargo durante la Época Moderna esa obligación se encontraba en completo desuso, dada la abundancia de miembros del estamento nobiliario dentro de las diferentes fraternidades ${ }^{32}$.

Los terciarios, como cristianos, tenían que cumplir las obligaciones impuestas a todos los creyentes. Pero, además, como miembros de una orden, contaban con una serie de obligaciones que iban más allá en cuanto a respeto al rigor de la vida cristiana. Por ejemplo, era obligatorio comulgar al menos tres veces al año: por

\footnotetext{
31 "El comer y beber de los sanos sea moderado, como dice el texto evangélico. Mirad no sean vuestros corazones agravados por la abundancia del comer y beber". REGLA de la Venerable Orden Tercera...,Caps. IV y V.

${ }^{32}$ Los estatutos generales señalaban: "pueden los hermanos de esta orden, aunque sean aquellos a quienes se les permite llevar el hábito descubierto ceñir espada, porque este genero de armas se ha reducido a decencia y ornato de los hombres". CANO, Fr. M. Regla de la Tercera Orden de Penitencia..., p. 9.
} 
Navidad, Pascua de Resurrección y Pentecostés. Se recomendaba también la asistencia a misa todos los días y se obligaba a la celebración de una eucaristía en fraternidad al menos una vez al mes ${ }^{33}$. Del mismo modo, en la capilla o sede de la V.O.T. se debía rezar diariamente el rosario al atardecer, una vez los hermanos terminasen sus trabajos. Había a lo largo del año litúrgico una serie de celebraciones franciscanas de ineludible cumplimiento: las misas por santos terciarios, la procesión del cordón, las funciones de las llagas de San Francisco, San Luis rey de Francia o Santa Isabel reina de Hungría -éstos últimos patronos de la V.O.T.-, etc. Por otro lado, se fomentaban los rezos propios de la orden, como era el caso de la corona.

La conmemoración de la pasión y muerte de Cristo ocupaba un destacado papel en el calendario terciario, comenzando por el rezo del Vía Crucis, devoción genuinamente franciscana, y continuando por los desfiles procesionales. En cuanto a lo primero, los terciarios leoneses lo rezaban al menos una vez al mes, en tiempo ordinario y todos los domingos en adviento y cuaresma, además de la mañana del viernes santo. La tarde del domingo de ramos, toda la fraternidad procesionaba por las calles de la ciudad acompañando a su imagen del Nazareno -conocido popularmente como el "Dainos"-, como especifican nítidamente sus ordenaciones particulares:

"El domingo de ramos saca la tercera orden en procesión la imagen de Jesús Nazareno, que
tiene en su capilla, y llegando a la plaza mayor, que llaman de San Martín, se pone la santa
imagen en una mesa, que tiene prevenida a este fin con un tapete los vicarios de el culto
divino, quienes tambien tienen puesto el paño en el pulpito a donde se ha de predicar, para lo
cual quedan de acuerdo antes con el predicador y le bienen acompañando, facilitando el
balcon donde ha de decir el sermon y para quando le acabe, le tendrán un hagasajo como es
justo, y por la mañana assean la santa imagen, cuydando de que se aprieten bien los
tornillos, de que tengan bastantes luzes, sacando de la cerería doce hachas y tendrán
prevenidas las horquillas para sostener las andas. El ministro está algunos días antes con el
padre guardián, suplicándole embie algunos religiosos, que serán seis u ocho, para que
vayan en la procesión cantando: Dadnos Señor buena muerte, por tu Santísima muerte: y
María Madre de gracia, Madre de misericordia, libradnos del enemigo en nuestra última
hora, 34 .

En ambas devociones queda reflejada de manera notoria otra de las obligaciones de la orden. El terciario no podía conformarse exclusivamente con impregnar su vida con la impronta de la humildad y la pobreza. También estaba obligado a predicar con el ejemplo, a evangelizar a la sociedad siguiendo estrictamente las

33 Arbiol, Fr. A., Los terceros hijos de el Humano..., p. 17.

${ }^{34}$ CANO, Fr. M. Regla de la Tercera Orden de Penitencia..., p. 55-56. 
directrices de la Iglesia postridentina. Por eso, los miembros de la fraternidad leonesa, al igual que sus hermanos del resto del mundo, salían a la calle recitando la doctrina y contrataban a un reputado predicador para que, en la plaza principal de la ciudad, aleccionase a sus vecinos. Nótese también la importancia que los terciarios ponen en la participación en estas celebraciones de los frailes de la primera orden. Esta unión de religiosos y seglares en actos de estas características, Fr. Bernardino de Sena la consideraba del todo necesaria "para que el pueblo se edifique y sepa que los religiosos y terceros hazemos un cuerpo y en las obras de virtud nos unimos en fin como hijos de un mismo Padre" ${ }^{\text {" }}$.

Muy ligada a esa permanente conmemoración de la pasión de Cristo está la dimensión penitencial de la orden. Ya señalamos las obligaciones a las que se comprometían los terciarios en cuanto al respeto al ayuno y abstinencia o su desprecio a todo lo que se consideraba superfluo y vano en la vida cotidiana. Pero la dimensión más evidente de su espíritu penitencial se encontraba, sin duda, en los ejercicios de mortificación. No estamos hablando de un comportamiento excepcional dentro de la religiosidad postridentina; estas prácticas eran comunes dentro de las órdenes regulares y aún fuera de ellas tras la configuración de las cofradías de disciplinantes en el Medievo ${ }^{36}$. No obstante y a diferencia de las cofradías de sangre, los terciarios no desarrollaban estas prácticas penitenciales de manera pública, sino que las ejecutaban en su capilla a puerta cerrada. Se trataba pues de una interiorización de la penitencia, que aunque mantenía su carácter ejemplar, rehuía del efectismo propagandístico barroco. En el caso leonés, la disciplina estaba integrada dentro de los ejercicios espirituales que celebraban los terciarios todos los viernes del año. La hora de entrada en la capilla era siempre "al acabar la campana que llaman el hayjón de maitines de la Santa Iglesia Cathedral". Evidentemente, en tiempo litúrgico de penitencia y, sobre todo, durante la Semana Santa, estas prácticas se hacían más frecuentes y prolongadas. Junto al sacrificio físico se efectuaban otra serie de ritos vinculados al desarrollo de un espíritu humilde o a la tan manida idea de la fugacidad de la vida:

"En tiempo de Quaresma, después de la estación nombran los maestros de ceremonias seis hermanos que a tres por cada vanda o lado lleven uno una vela, otro una calabera y otro un crucifijo y van diciendo el de la calabera a cada hermano: acuerdesse hermano, que se ha de morir y el que lleva el crucifijo: y este Señor le ha de juzgar. Algunos dias de quaresma en lugar de esta ceremonia se nombran quatro o seis hermanos que cada uno en el trecho que se

${ }^{35}$ SENA, Fr. B. Ordenaciones generales para el mejor..., pp. 47-48.

${ }^{36}$ SÁNCHeZ J. (1997). «Las cofradías de Semana Santa durante la modernidad. Siglos XV a XVIII», en. I Congreso nacional de cofradias de Semana Santa. Zamora: Diputación Provincial de Zamora, pp. 27-68, y 29 y ss. 
señala van besando los pies y abrazando a cada hermano y le dice: perdóneme hermano por amor de Dios; y los primeros que hacen esta ceremonia y acto de humildad son el padre visitador y ministro ${ }^{, 37}$

La labor asistencial jugaba también un papel de primera importancia en la vida de la tercera orden. Nicolás IV dividía el dinero que debía aportar el terciario a su comunidad para dos fines: el reparto como limosna entre los hermanos más necesitados "y principalmente los enfermos" y el sostenimiento espiritual -misas, sermones, etc. ${ }^{38}$. Fr. Bernardino de Sena especificaba que a los pobres de solemnidad debía socorrérseles, por una vez, con doce reales de vellón, buscándose entre el padre visitador y la junta la solución más adecuada en caso de que esa situación de penuria se mantuviese. Los estatutos generales, además, sugerían la necesidad de que en momentos de dificultades económicas para la fraternidad, fuesen los propios hermanos los que particularmente sostuviesen con sus limosnas al caído en desgracia. En cuanto a la asistencia a los enfermos, el hermano ministro tenía como obligación en la regla de 1289, visitarlos todas las semanas, exhortándoles a la confesión e interesándose también por el estado material de sus haciendas. Sin embargo, a partir del siglo XVII, buena parte de estas obligaciones las asumió el enfermero mayor. En León existían dos, un seglar y un eclesiástico que, si fuera posible, debían salir de las filas de los exministros de la fraternidad y, en todo caso, "de los más antiguos que sean ejemplares". Su misión era visitar "con charidad y amor" a los hermanos enfermos, informando a la junta de las necesidades que observasen. Desde luego, un medio más eficaz para la asistencia de los hermanos convalecientes era la creación de hospitales propiamente dichos. La existencia de centros hospitalarios creados y administrados por la V.O.T. está ya documentada desde el Medievo y esta vocación no se perdió en los siglos de la Edad Moderna, como nos muestran las fundaciones de Oporto o Madrid. Sin embargo, estas magnas obras requerían de unas inversiones que solamente podían sostener las fraternidades más populosas y ricas. La V.O.T. de León, por tanto, se conformaba con la asistencia a través de las figuras del enfermero mayor o el visitador de cárceles y hospitales, en caso de que el hermano se encontrase recluido en alguno de esos establecimientos ${ }^{39}$. Además, para tener un conocimiento de primera mano de los terciarios enfermos, se instituyó también la figura de los enfermeros menores, que se encargaban de informar puntualmente a los mayores y a la junta, de los hermanos enfermos en su circunscripción. En concreto, en León

\footnotetext{
${ }^{37}$ CANO, Fr. M. Regla de la Tercera Orden de Penitencia..., p. 44.

${ }^{38}$ REGLA de la Venerable Orden Tercera..., Cap. 13.

${ }^{39}$ Los visitadores de hospitales y cárceles eran también dos en el caso leonés.
} 
existían un total de diecinueve, distribuidos por todas las parroquias de la ciudad ${ }^{40}$. $\mathrm{La}$ asistencia a los hermanos pobres también se extendía a aquellos forasteros que, una vez comprobada su verdadera pertenencia a la orden, solicitasen de la fraternidad leonesa una caridad. En la documentación aparecen denominados como "hermanos peregrinos" y se les concedía, por una sola vez, cuatro reales de vellón, en caso de ser clérigo, y dos si era seglar ${ }^{41}$.

Junto a la necesaria asistencia durante la vida, era capital el acompañamiento en la muerte. Al menos teóricamente, era de obligado cumplimiento la presencia en las exequias de los hermanos fallecidos, de las cuales no se podían marchar hasta que "los oficios solemnes sean acabados y el cuerpo sea sepultado". Además, en el plazo de ocho días, había obligación de escuchar una misa por el finado y rezar cincuenta salmos -aquellos que supiesen leer- $u$ otros tantos "pater noster" ${ }^{\text {" }}$. Si bien de los rezos no fueron en ningún momento eximidos, lo cierto es que el acompañamiento a la sepultura fue una obligación que, poco a poco, desapareció. En los estatutos de 1689 se permitía ya obtener la dispensa de ese acto aunque se intentaba promover la iniciativa voluntaria a través de esta inquietante afirmación: "acuérdese siempre que como nosotros hicieremos con los difuntos assi dispondrá o permitirá Dios hagan con nosotros los que vivan después de nuestra muerte". En el León de mediados del siglo XVIII, se recomendaba la presencia de todos los miembros de la fraternidad en este doloroso acto aunque se apostillaba que "a lo menos han de ir doce que serán avisados en sus casas", síntoma inequívoco de la escasa respuesta del conjunto de hermanos ${ }^{43}$. Este ambiente de indiferencia se mantuvo hasta bien entrada la siguiente centuria. El 6 de enero de 1828, se sacaba a relucir el problema en la junta de gobierno de la orden:

${ }^{40}$ La distribución era la siguiente: 2 para San Martín, 2 para San Marcelo, 2 para San Juan de Regla. 4 para San Isidro y Santa Marina, 3 para San Salvador del Nido, San Pedro de los Huertos y San Lorenzo, 2 para Santa Ana, 2 para el Mercado y otros 2 para San Salvador de Palat de Rey.

${ }^{41}$ En la década de los veinte del siglo XIX el monto de la limosna se había incrementado: en 1825 se le concede a un hermano transeúnte 12 reales, un año más tarde a otro 8. Es posible que la diferencia económica estuviera relacionada con el estado del peregrino -eclesiástico en el primer caso y seglar en el segundo-. CANO, Fr. M. Regla de la Tercera Orden de Penitencia ..., p. 57; A.V.O.T.L., Libro de cuentas (1822-1833), fol. 15.

${ }^{42}$ REGLA de la Venerable Orden Tercera..., Cap. 14.

${ }^{43}$ Esos doce hermanos debían pertenecer seis al estado eclesiástico y los otros seis al seglar. Esta obligación iba rotando mensualmente entre todos los miembros de la fraternidad. CANO, Fr. M. Regla de la Tercera Orden de Penitencia..., pp. 16 y 51. 
"Se trató de la mala asistencia que se advertía a los entierros de los hermanos y después de un detenido examen se acordó que el R.P. visitador en el primer domingo de Cordón estimule cuanto le sea posible a la asistencia de un acto tan caritativo; que se lea en cada uno la lista de los 12 hermanos que a lo menos deben asistir a los entierros por meses, cuya lista pondrán en la capilla todos los meses y domingos de cordón los hermanos síndicos menores, la cual despues de leida se ha de colocar en la capilla para cada hermano se entere si está o no de servicio en el mes: y cuando no pueda hacerle está obligado a buscar otro hermano que le sustituya, y el hermano sirviente á avisar a cada uno de los 12 en sus propias casas ",44.

Como sucedía en otras fraternidades, se intentó eliminar aquellas obligaciones que podían generar mayores reticencias entre los terciarios. Ese es el motivo del nacimiento de los denominados "hermanos de caridad", cuya misión era portar en sus hombros el féretro del fallecido. De esta manera se eliminaba una de las cargas más pesadas que debían soportar los miembros de la fraternidad. Los hermanos de caridad recibían de la orden una propina por su trabajo, amén de la obtención, de vez en cuando, de ropa y calzado. Esta solución, no sólo no acabó con el problema sino que, además, generó nuevos inconvenientes: en ocasiones, los hermanos de caridad se olvidaban del espíritu de pobreza franciscano para exigir a los herederos del difunto más dinero, originándose algún que otro altercado con el propio discretorio $^{45}$.

Para que la fraternidad actuase activamente en las ceremonias fúnebres era necesario que el hermano hubiese ya profesado -aunque tomase el hábito en el lecho de muerte- además de tener sus contribuciones económicas a la hermandad más o menos al día. Esto no quiere decir que el discretorio no se sensibilizase con las tragedias personales de algunos de los hermanos: cuando en 7 de enero de 1796 fallecía el comerciante D. José García de Velasco, se celebraban todos los actos fúnebres a pesar de deber más de tres años de conmutaciones "por haber benido a la pobreza". No se trata de un caso aislado; los estatutos particulares estipulaban la necesidad de sostener los entierros de los hermanos pobres de solemnidad y no es infrecuente su sepultura en la propia capilla de la tercera orden ${ }^{46}$. Los entierros en el templo de la fraternidad estaban reservados exclusivamente a los hermanos profesos y, a diferencia de lo que sucedía en otras localidades, los leoneses sí

\footnotetext{
${ }^{44}$ A.V.O.T.L., Libro de acuerdos (1826-1888), fols. 11 y 11 vto.

45 Así sucedió en mayo de 1829, cuando los hermanos de caridad exigieron a los herederos de la hermana $\mathrm{D}^{\mathrm{a}}$. Francisca García, del arrabal de San Lorenzo, "igual propina que le da la T.O.”. La junta de gobierno acordó despedir del oficio a varios de ellos. A.V.O.T.L., Libro de acuerdos (1826-1888),

${ }^{46}$ D. Benito Unzue fue enterrado en octubre de 1787 en esas circunstancias. A.V.O.T.L., Libro de entradas de hermanos, fols. 41 y 60.
} fol. 18 vto. 
hicieron valer ese privilegio. Entre 1763 y 1808 se enterraron en la capilla de la tercera orden un total de 433 hermanos -228 mujeres y 205 hombres $^{47}$-. El análisis evolutivo (gráfico 1) nos muestra una tendencia ascendente durante la segunda mitad del siglo XVIII que se frena a comienzos del XIX, momento de la prohibición de los enterramientos en las iglesias. Por otro lado, hallamos en esos enterramientos a buena parte de los miembros más selectos de la fraternidad: el 49\% de las mujeres y el 58\% de los hombres poseen el título de Don/Doña. Incluso nos topamos con un título de Castilla, el marqués de San Isidro, sepultado el 2 de septiembre de 1768. Llama también la atención el especial interés que tenían los hermanos clérigos por enterrarse en el templo tercero: durante el período hicieron lo propio un total de 15 eclesiásticos, algunos de ellos párrocos de feligresías rurales del entorno, además del caso un tanto excepcional del franciscano Fr. Tomás García, padre visitador, que fue sepultado el 7 de mayo de 1775.

Los terciarios tenían como obligación enterrarse con el hábito de su orden ${ }^{48}$. Aún así es notorio que fueron muchos los fieles no integrados en la V.O.T. que optaron por la mortaja franciscana ${ }^{49}$. Ante la carencia de un conocimiento profundo de las verdades de la fe, el hombre del Antiguo Régimen apelaba a estas muestras externas como alivio a sus angustias frente al dilema de la salvación. Por otro lado, los sectores acomodados de la sociedad -nobleza y alta burguesía- veían en el hábito franciscano un medio para relacionarse, en el momento crucial de la muerte, con los pobres, representados por San Francisco y sus sucesores. Se trataba de un intento de acercamiento de última hora a una austeridad de la que nada quisieron saber a lo largo de su vida ${ }^{50}$. Para evitar estos comportamientos o al menos, para beneficiarse adecuadamente de ellos, los terciarios incrementaron de manera

${ }^{47}$ A.V.O.T.L., Libro de enterramientos y de inventario (1763).

48 GonZÁlEZ, D. (1989). «"La mortaja religiosa en Santiago entre los siglos XVI y XIX». Compostellanum, pp. 271-295 y 277.

${ }^{49}$ Se trata de un comportamiento extrapolable a todo el mundo católico. Las investigaciones del profesor Laureano Rubio han constatado esa realidad en el caso específico del reino de León durante los siglos XVII y XVIII. Tanto en la comarca de La Bañeza como en la propia capital, el hábito franciscano era, con mucho, la mortaja preferida por los testadores. RuBiO, L. (1987). La Bañeza y su tierra, 1650-1850. Un modelo de sociedad rural leonesa. León: Universidad de León, pp. 458 y ss; RuBiO, L. (1986). «Estructura social y mentalidad religioso-colectiva en la ciudad de León durante los siglos XVII y XVIII». Revista Internacional de Sociología, pp. 609-646.

${ }^{50}$ BARREIRO, B. (1984). «La nobleza asturiana ante la muerte y la vida», en, EIRAS, A., (dir.). La documentación notarial y la historia, Salamanca: Universidad de Santiago, Vol. I, pp. 27-60; REY, O. (1981). «El clero urbano compostelano a fines del siglo XVII: mentalidades y hábitos culturales», en, EIRAS, A. y OTROS. La historia social de Galicia en sus fuentes de protocolos. Santiago: Universidad de Santiago, pp. 485-519. 
significativa las limosnas exigidas por noviciado y profesión a las personas de edad avanzada y mucho más si cabe a las que tomaban el hábito en el lecho de muerte. Con esta medida, además de los beneficios económicos que podían reportar, se trataba de evitar agravios comparativos con los hermanos que durante años pagaban religiosamente sus conmutaciones.

\section{LA ORGANIZACIÓN INTERNA DE LA V.O.T.}

Para el correcto funcionamiento de la orden, tanto desde el punto de vista espiritual como material, existían una serie de cargos que se renovaban anualmente. A pesar de que a la hora de tomar el hábito terciario no se ponía impedimento a ningún sector de la sociedad por muy humilde que fuera, para el gobierno de la fraternidad eran sus miembros más selectos los que monopolizaban los cargos. Existían dentro de la orden dos grupos claramente diferenciados: los "oficiales de voto", es decir, aquellos que podían intervenir en las elecciones y el resto de hermanos que, a pesar de gozar de los mismos privilegios espirituales, les estaba vedada su intervención en el gobierno. En los estatutos particulares de la V.O.T. leonesa, la elite intentaba justificar su preeminencia de manera un tanto hipócrita:

"y porque sería grandísima confusión recibir los votos de todos los hermanos para las elecciones, se manda que en ellas no tengan voto, sino los que le tienen en las juntas de cada mes, 51

Todas las fraternidades estaban encabezadas por un ministro, cargo que se elegía anualmente en junta que solía celebrarse a finales del mes de diciembre. Podía ser tanto un seglar como un eclesiástico, aunque se debía procurar que se fueran alternando en la cargo los miembros de ambos estados. Esta regla se rompió en León a partir de 1832, dada la escasez de sacerdotes con los que contaba la fraternidad en aquellos tiempos. Por ese motivo, el 14 de noviembre de aquel año, y a petición de la junta de gobierno, el padre provincial autorizó que la alternancia no fuera anual, sino que los seglares presidiesen dos años seguidos por uno los eclesiásticos $^{52}$. El papel de los frailes del convento de San Francisco en la elección de los principales cargos de la V.O.T. era realmente importante. El padre guardián o su delegado presidían las votaciones y solamente ellos podían proponer la reelección del ministro si consideraban que era "muy a propósito para este

${ }^{51}$ CANO, Fr. M. Regla de la Tercera Orden de Penitencia..., p. 31.

52 En aquel momento sólo había seis hermanos eclesiásticos. A.V.O.T.L., Libro de acuerdos (1826-1888), fol. 141. 
empleo", si bien esa propuesta había de ser ratificada por los electores. También el ministro saliente jugaba un papel más que destacado pues, si no era reelegido, era él quien proponía los seis candidatos a sucederle -tres seglares y tres eclesiásticos-.

El ministro asistía a todas las celebraciones de la orden y velaba porque todos los cargos cumpliesen con su cometido. Era también el principal responsable de la correcta vida de los hermanos, por lo que tenía obligación de informar al padre visitador de aquellos terciarios que no cumplían con sus obligaciones. De igual modo, en él recaía la última responsabilidad del buen funcionamiento, tanto en lo material como en lo espiritual, de la fraternidad. Para sustituirlo en momentos de ausencia, se elegía un viceministro o coadjutor. La costumbre y las recomendaciones de estatutos y ordenaciones aconsejaban que cuando el ministro fuera seglar el coadjutor perteneciese al estado eclesiástico y viceversa ${ }^{53}$. Sin embargo, en León en junta celebrada en 13 de enero de 1793, se acordó que ambos cargos los desempeñaran miembros del mismo estado pues "hera poco decente que el viceministro eclesiástico llebase la hizquierda del ministro secular". La segunda autoridad, a la misma altura que el ministro, era el padre visitador. Se trataba de un fraile menor al que sus superiores le habían disculpado de sus obligaciones conventuales para asistir a la V.O.T. ${ }^{54}$. Entre sus funciones se encontraba la de exhortar y amonestar a todos los hermanos al seguimiento de la regla y estatutos, así como cuidar de la corrección espiritual de la comunidad. Debía asistir a todas las juntas y actos públicos y secretos con el ministro y el resto de oficiales. Presidía las celebraciones religiosas y, como principal responsable en el campo pastoral, se responsabilizaba de la visita a los pobres y enfermos "haciendoles alguna platica exortatoria quando se les lleva de comer". En el caso leonés esas dimensiones pastorales estaban un tanto incrementadas, pues debía visitar al menos una vez al año -y siempre que no lo hiciese el padre guardián-, a los hermanos terciarios de la guardanía, es decir, a los no residentes en la ciudad.

Por debajo de ministro y visitador se encontraban los discretos. Como en el caso del primero, su elección se restringía a aquellos hermanos más reputados desde el punto de vista social, motivo suficiente como para ocupar un lugar de privilegio en el gobierno de la V.O.T. Su número variaba según la importancia de la fraternidad. En aquellas más importantes, como en León, se recomendaba que hubiese veinticuatro, sin contar al ministro y al coadjutor. A estos puestos podían optar

${ }^{53}$ SENA, Fr. B. Ordenaciones generales para el mejor..., p. 59.

54 En la regla nicolasiana no se obliga sino que se recomienda que el visitador sea un fraile menor. REGLA de la Venerable Orden Tercera... Cap. 16. 
tanto hermanos seglares como eclesiásticos y aunque no existía impedimento alguno para que todos los cargos fuesen ocupados por un único sector, lo cierto es que los estatutos generales de 1689 abogaban por un cierto equilibrio ${ }^{55}$. Los discretos estaban obligados a asistir a todas las juntas y celebraciones religiosas, para dar ejemplo a los demás. Cuando por enfermedad no pudieran, debían mandar una excusa por escrito. Ellos, junto con el ministro, el coadjutor y el visitador, formaban la junta de gobierno de la V.O.T. o discretorio. En ella se trataban los principales asuntos, tanto espirituales como materiales de la fraternidad. Sólo ella podía autorizar una determinada obra en la capilla, también estipulaba las cantidades que los hermanos debían entregar en concepto de limosna a la fraternidad o daba luz verde a las acciones legales que fueran menester contra aquellas personas o instituciones que menoscababan los privilegios y derechos de la orden. Se recomendaba la celebración de una junta al menos cada mes. En ella tenía que estar siempre presente bien el visitador, bien el padre guardián del convento o un delegado de aquel. Asimismo, debía contar la reunión con un mínimo de cuatro discretos y el secretario. Si no se cumplía ese requisito, los acuerdos tomados no eran válidos. Presidían la junta el ministro y el visitador en dos sillas iguales. Se comenzaba siempre leyendo la última acta y en el momento de la votación, el voto decisivo en caso de empate lo tenía el visitador o el guardián. Para dar constancia de los acuerdos tomados en las juntas también participaba el secretario, que hacía las veces de notario de la fraternidad y que en León "porque el trabajo es grande" contaba con un vicesecretario.

Junto a todos estos cargos existían otros relacionados con la gestión económica de la orden -contadores-, el buen desarrollo de las ceremonias religiosas -maestros de ceremonias, vicarios del culto divino, lectores- o el control ideológico y moral de hermanos y postulantes - maestros de novicios y celadores-, sin olvidar los vinculados a la labor asistencial -enfermeros y visitadores de cárceles y hospitales $-^{56}$. Por debajo se encontraban los desempeñados por terciarios de

${ }^{55}$ ARBIOL, Fr. A. Los terceros hijos de el Humano..., p. 23.

${ }^{56}$ En León había cuatro síndicos, uno mayor y tres menores. Los menores se encargaban de la recolección de limosnas que custodiaba y gestionaba el mayor "sin que puedan estar en poder de otro un solo dia". Los maestros de ceremonias eran dos, elegidos entre los discretos eclesiásticos, y su función consistía en la organización de los actos religiosos. Los vicarios de culto divino -tres "eclesiásticos o seculares"- cuidaban de la decencia de la capilla, mientras que los lectores -cuatro clérigos- se ocupaban de recitar las obras de meditación empleadas en los ejercicios. Por último, había dos maestros de novicios - uno de cada estado- encargados del adoctrinamiento de aquellos hermanos hasta su profesión y diecinueve celadores -que hacían también la función de enfermeros menorescon la misión de "mirar con prudencia, secreto y charidad el modo con que viven los hermanos de sus distritos y como guardan la regla y constituciones". Todos estos cargos, excepción hecha del contador 
extracción social más baja y que, evidentemente, no gozaban del mismo prestigio dentro de la orden. Estos oficios estaban supeditados a la autoridad de alguno de los otros anteriormente señalados. En León, los cuatro sirvientes o criados de la orden eran hermanos con hábito descubierto, que se rotaban mensualmente como sacristán, avisador, sacador y campanero ${ }^{57}$.

Una característica particularmente interesante en la configuración interna de las órdenes terceras seglares era el papel desempeñado por las mujeres. Las terciarias contaban dentro de la fraternidad con una organización paralela a cuya cabeza se hallaba una hermana ministra -elegida entre una terna propuesta por el ministro ${ }^{58}$ auxiliada por sus discretas y otros cargos menores de entre los que destacaba la maestra de novicias. Evidentemente, no participaban en las decisiones de la junta de gobierno y en todo momento estaban sometidas a la autoridad de los hombres pero, de todas maneras, esta relativa autonomía no deja de resultar curiosa en una sociedad como la del Antiguo Régimen.

Una vez elegidos, los cargos eran confirmados en el "capítulo anuo" que se celebraba en el domingo del cordón del mes de enero y al que asistían todos los hermanos de la fraternidad leonesa. Se trataba más bien de una ceremonia de investidura puesto que los terciarios no electores no tenían posibilidad alguna de impugnar la decisión tomada. Tras las oraciones y pláticas de rigor, el ministro saliente, de rodillas ante el fraile que presidía la ceremonia "pedirá con humildad penitencia de sus faltas y el presidente le dará las gracias de el desvelo y cuydado que ha tenido o le amonestará charitativamente si acaso tuvo algún descuydo". Después se leía ante todos los hermanos la tabla de oficios para el nuevo ejercicio y el ministro entrante era confirmado por el fraile. De igual manera, se utilizaba esa junta para que el secretario hiciese relación de los ingresos y gastos del año anterior, así como de los nuevos hermanos y los fallecidos ${ }^{59}$.

mayor, eran elegidos directamente por el ministro junto al secretario y "dos hermanos los más zelosos". CAno, Fr. M. Regla de la Tercera Orden de Penitencia ..., pp. 22 y ss.

${ }^{57}$ El sacristán tenía como misión abrir la capilla y ayudar en las celebraciones religiosas. El avisador informaba a los oficiales de las convocatorias de junta, así como del fallecimiento de hermanos o de su estancia en cárceles u hospitales. El sacador era el encargado de portar la saca de las limosnas en las ceremonias de la orden y el campanero de anunciar por las calles las celebraciones. Ibid., pp. 27 y ss.

\footnotetext{
${ }^{58}$ La viceministra salía de entre las dos no elegidas para el principal cargo.

${ }^{59}$ Cano, Fr. M. Regla de la Tercera Orden de Penitencia ..., p. 33-34.
} 


\section{LAS BASES SOCIALES Y ECONÓMICAS DE LA V.O.T. LEONESA}

La lamentable pérdida de buena parte de la documentación más antigua, nos impide concretar la fecha de fundación de la fraternidad leonesa. No obstante, considerando su inclusión dentro de la provincia franciscana de Santiago, lo normal es que se produjera entre las últimas décadas del siglo XVII y las primeras del XVIII. Este encuadre no es caprichoso, sino que responde a las pautas de desarrollo de la tercera orden en otras zonas de la provincia, como por ejemplo, el reino de Galicia. Sea como fuere, tantos los registros de entradas de varones (gráfico 2) como de mujeres (gráfico 3) nos hablan de un proceso de consolidación y crecimiento a partir de las décadas centrales del XVIII. En el caso masculino, la documentación es demasiado fragmentaria como para realizar afirmaciones categóricas -solamente contamos con las entradas entre 1735 y 1775-. Aún así, se observa un más que notable incremento de las tomas de hábito en la década de los cincuenta que coincide con los mucho más fiables registros de mujeres. Asimismo, en ambos sexos se atisba una caída en los sesenta que, en el caso femenino, da paso a un fuerte incremento de vocaciones en los dos decenios posteriores especialmente en los ochenta- ${ }^{60}$. El cambio de tendencia se produce durante los últimos años de la centuria, período marcado por una profunda inestabilidad económica, social y política. A partir de entonces y hasta el fin de la Guerra de Independencia, las vocaciones caerán en picado, produciéndose después cierta recuperación que no podemos valorar en su justa medida por las carencias de las fuentes.

Los registros de tomas de hábito no solamente sirven para realizar un estudio evolutivo de las vocaciones en la fraternidad leonesa. También pueden ser empleados para calibrar el grado de compromiso de los hermanos con el franciscanismo. Si tenemos en cuenta que los integrantes de la V.O.T. tenían que pasar por un período de noviciado antes de poder profesar como miembros de pleno derecho, resulta de especial interés analizar cuántos eran los que lograban dar el salto definitivo y cuántos se quedaban por el camino. Desde luego, en el caso leonés, eran pocos los hombres y mujeres que renunciaban a la profesión: de los 138 varones registrados entre 1735 y 1775, solamente uno no siguió adelante. En el caso femenino, entre 1750 y 1817 , los resultados no son tan contundentes, aunque el porcentaje de hermanas que optaban por la profesión era también abrumador: el $81,2 \%$-556 de las 685 contabilizadas-. Otro aspecto de interés es dilucidar el

${ }^{60}$ Desde la década de los setenta en adelante solamente contamos con los registros de hermanas. Sin embargo, dadas las coincidencias observadas para períodos anteriores, creemos que su análisis evolutivo puede ser extrapolable para el conjunto de la fraternidad. 
tiempo que trascurre entre el noviciado y la profesión. Tanto las disposiciones generales como las particulares estipulaban el año como el marco adecuado para la formación del hermano $\mathrm{y}$, en efecto, en la gran mayoría de las ocasiones los novicios atendían a estas recomendaciones: el $88,3 \%$ de las mujeres y el $74,3 \%$ de los hombres así lo hicieron. Además, el porcentaje subiría al 95,9\% y 88,9\% respectivamente si pusiésemos como plazo los dos años. Este cumplimiento estricto del período de noviciado está muy relacionado en el caso leonés con las medidas coercitivas desarrolladas por la junta de gobierno de la V.O.T. que enlazan directamente con medidas similares tomadas por otras fraternidades de la época. Se trataba de gravar onerosamente a aquellas personas que, una vez tomado el hábito de novicio, se desentendían de las obligaciones espirituales y económicas para con la orden hasta la hora postrera de la muerte. Para evitar estos comportamientos se imponían a los infractores unas penas económicas tan importantes que desaconsejaban por completo este tipo de prácticas.

Si para el análisis evolutivo de las tomas de hábito nos hemos tenido que basar fundamentalmente en el sector femenino, algo similar acontece con el estudio de las zonas de residencia de los hermanos. Esta información, que aparece en la gran mayoría de las partidas de entrada de las mujeres, lo hace de manera muy esporádica en las de los hombres. Debemos ser pues muy cautos a la hora de generalizar los comportamientos, si bien, habida cuenta del importante número de matrimonios que optan a la vez por ingresar en la orden, pensamos que los resultados sino exactos deben ser muy aproximados:

\begin{tabular}{l|r|r}
\hline \multicolumn{1}{c|}{ Parroquia } & Total & $\%$ \\
\hline San Martín & 166 & 30,9 \\
N $^{\text {. S }}$. del Mercado & 75 & 14,0 \\
San Juan de Regla & 72 & 13,4 \\
San Marcelo & 66 & 12,3 \\
Santa Marina & 59 & 11,0 \\
San Salvador del Nido & 30 & 5,6 \\
Palat de Rey & 22 & 4,1 \\
San Pedro de Huertas & 13 & 2,4 \\
San Isidro & 12 & 2,2 \\
Corredera & 8 & 1,5 \\
Santa Ana & 6 & 1,1 \\
San Juan de Renueva & 6 & 1,1 \\
San Lorenzo & 2 & 0,4 \\
\hline TOTAL & 537 & 100,0 \\
\hline
\end{tabular}


Solamente el $12,1 \%$ de las terciarias residían en los arrabales de la ciudad ${ }^{61}$. El resto habitaban murallasa dentro, destacando especialmente la aportación de la parroquia de San Martín. Esta preeminencia es del todo lógica si consideramos que en 1751 el $30 \%$ de la población leonesa residía en aquel barrio, porcentaje prácticamente igual al que obtenemos en el vaciado de los libros de entradas ${ }^{62}$. Por detrás se encuentran otras parroquias también populosas como el Mercado, San Juan de Regla y San Marcelo que junto a Santa Marina, constituían las zonas predilectas de residencia de las elites de la ciudad ${ }^{63}$. Y es que no pocos miembros reputados de la sociedad leonesa tomaron el hábito terciario durante el XVIII: el $78,3 \%$ de los hombres y el $40,1 \%$ de las mujeres son calificados en las fuentes como "Don" o "Doña" "64. Algunos, ciertamente, ocupaban un lugar de especial relevancia. En junio de 1758 ingresaba como novicio D. Melchor Sanz de Tejada, alcalde mayor de la ciudad, profesando un año después. Un tiempo más tarde, en abril de 1791, hacía lo propio $\mathrm{D}^{\mathrm{a}}$. Jacoba de Coca, esposa del vizconde de Quintanilla ${ }^{65}$. Si atendemos a los datos ofrecidos por los registros de entradas masculinos, también el clero y la burguesía se aproximaron con entusiasmo al modo de vida terciario ${ }^{66}$ :

\begin{tabular}{l|r|r}
\hline \multicolumn{1}{c|}{ Profesiones } & Total & $\%$ \\
\hline Clero & 38 & 36,9 \\
Profesiones Liberales & 27 & 26,2 \\
Comercio & 14 & 13,6 \\
Artesanado & 11 & 10,7 \\
Tenderos & 6 & 5,8
\end{tabular}

${ }^{61}$ Consideramos los arrabales las siguientes parroquias: Renueva, Sta. Ana, S. Salvador del Nido, Corredera, S. Pedro de los Huertos, S. Lorenzo, Palat de Rey.

${ }^{62}$ Martín, J. L. (1957). La ciudad de León en el siglo XVIII. Biografia de una ciudad, León, p. 65.

63 Rubio, L. (1993). León 1751 según las Respuestas Generales del Catastro de Ensenada. Madrid: Tabapress, p. 82.

${ }^{64}$ Las cifras son las siguientes: 108 de los 130 hombres registrados entre 1736 y 1773 y 275 de las 685 mujeres entre 1739 y 1817. Los datos son elocuentes a pesar de que sea posible en el caso de los varones que se halla producido cierta distorsión.

65 D. Melchor Sanz pagó religiosamente sus limosnas hasta su marcha de la ciudad a finales de 1761. Por su parte, la vizcondesa no llegará nunca a profesar. A.V.O.T.L., Libro de entradas de hermanos, fol. 391.

${ }^{66}$ De las 136 partidas, 103 cuentan con la información requerida, es decir, el 75,7\%. 


\begin{tabular}{l|r|r} 
Servicio Doméstico & 3 & 2,9 \\
Músicos & 2 & 1,9 \\
Otros & 2 & 1,9 \\
\hline TOTAL & 103 & 100,0 \\
\hline
\end{tabular}

El clero leonés jugó un papel de especial relevancia en la fraternidad durante el siglo XVIII. Baste un dato para evidenciar ese protagonismo: si en el León de 1751 representaba el 6,2\% del vecindario, en la V.O.T. su importancia dentro del sector masculino se disparaba hasta el $37 \%{ }^{68}$. De entre el conjunto clerical debemos destacar la importancia desempeñada por los miembros del cabildo catedralicio y los canónigos de San Isidro, con 10 individuos localizados. Estamos hablando de los sectores más acomodados y reconocidos dentro del estamento clerical. Por ese motivo, parece evidente primar como principal causa de ingreso en la V.O.T. los aspectos devocionales, pues en materia de privilegios espirituales tanto unos como otros estaban más que servidos. Hay casos especialmente interesantes en cuanto a la activa participación de este clero en la vida terciaria leonesa: en octubre de 1758 tomaba el hábito D. Antolín Barreda Yebra, en aquel momento simple canónigo y un tiempo más tarde abad del convento de San Isidro. En 1807, cuando aún ocupaba esa alta dignidad, donó a la tercera orden 30 pies de roble para las obras de entarimado de su capilla. Ante ese rasgo de generosidad, el discretorio decidió eximirle de las conmutaciones semanales ${ }^{69}$. Si no existía incompatibilidad alguna para que los sacerdotes ingresasen en la V.O.T. tampoco la había para la toma del hábito terciario por parte de miembros de órdenes regulares. En León esta circunstancia se muestra de manera mucho más palpable en el caso de las mujeres. Fueron numerosas las religiosas del convento de Carvajal y, sobre todo, de Santa Catalina que se incorporaron a la fraternidad terciaria durante el siglo XVIII. En el caso de las primeras podemos citar a $\mathrm{D}^{\mathrm{a}}$. Mariana Furió, monja profesa de aquel cenobio que ingresó en 1777. Años después, concretamente en 1789, hará lo propio otra religiosa, $\mathrm{D}^{\mathrm{a}}$. Teresa Evia. Más fecunda para la V.O.T. resultó su relación con el convento de Santa Catalina, a pesar de la regla que observaban sus integrantes la de Santo Domingo-. Fueron abundantes los casos de religiosas de aquel establecimiento que tomaron el hábito terciario: en 1784 lo hizo $\mathrm{D}^{\mathrm{a}}$. Josefa

${ }^{67}$ Un agricultor y un oficial del Ejército.

68 Los datos porcentuales manejados a partir del catastro de Ensenada (1751) proceden del estudio realizado por el profesor Laureano Rubio. Ver, RuBio, L. León 1751 según..., p. 15.

${ }^{69}$ A.V.O.T.L., Libro de entradas de hermanos, fols. 59 y 66. 
Quiñones Pimentel y un año después le siguieron $D^{\mathrm{a}}$. Eufemia Escobar y $\mathrm{D}^{\mathrm{a}}$. Petra Quiñones. La relación se mantuvo en la década de los noventa, en la cual otras hermanas del convento $-\mathrm{D}^{\mathrm{a}}$. María Reinaldo, $\mathrm{D}^{\mathrm{a}}$. María Alfonso, $\mathrm{D}^{\mathrm{a}}$. Antonia Arnay y Quiñones y su hermana $\mathrm{D}^{\mathrm{a}}$. Josefa- y una seglar $-\mathrm{D}^{\mathrm{a}}$. Manuela Cabeza de Vaca- abrazaron la regla de la tercera orden ${ }^{70}$.

Junto a la importancia desempeñada por el clero, otros miembros respetados de la sociedad leonesa, como comerciantes o profesionales liberales -abogados, escribanos, notarios y funcionarios de la real hacienda- participaron activamente de la vida terciaria. También en este caso su presencia es mucho más importante que su peso porcentual en el vecindario de la ciudad. Aún sin despreciar sus convicciones religiosas, la entrada en la V.O.T. podía suponer para los integrantes de estos sectores ese plus de prestigio que estaban demandando. El abanico de privilegios, tanto espirituales como de protocolo - no olvidemos el lugar destacado que ocupaba la V.O.T. en las ceremonias religiosas- eran demasiado apetecibles como para ignorarlos.

La diversidad social que hallamos en la fraternidad se completa con la presencia de las clases populares representada, entre otros, por artesanos, tenderos o criados. Es evidente que su volumen numérico en aquella distaba mucho de corresponderse con su verdadero peso en el conjunto de la población, sobre todo en cuanto al artesanado, sector socioeconómico mayoritario en la ciudad durante el XVIII y con presencia harto discreta en la fraternidad. Existe pues una preeminencia de las clases más acomodadas que puede estar relacionada con una política de restricción impuesta por los sectores dirigentes o, más bien, por las exigencias pecuniarias que comportaba la pertenencia a la orden que, posiblemente, no podían soportar la frágiles economías populares. Y es que las conmutaciones de los hermanos eran la principal fuente de ingresos de la fraternidad, como desvelan sus libros de cuentas del primer tercio del siglo $\mathrm{XIX}^{71}$ :

\begin{tabular}{c|r|r}
\hline Ingresos & Total & $\%$ \\
\hline Conmutaciones & 23.714 & 80,9
\end{tabular}

${ }^{70}$ A.V.O.T.L., Libro de entradas de hermanos, fols. 135, 209, 235, 236, 343, 441, 447, 520 y 521.

${ }^{71}$ La desaparición de los libros de cuentas del siglo XVIII hace que nuestra visión de la realidad económica de la tercera orden leonesa adolezca de cierto sesgo, máxime si tenemos en cuenta la depresión sufrida por el movimiento seglar franciscano en las primeras décadas del XIX. V.O.T.L., Libro de cuentas (1822-1833) 


\begin{tabular}{l|r|r} 
Otras limosnas & 5.221 & 17,8 \\
Censos & 372 & 1,3 \\
\hline TOTAL & 29.307 & 100,0 \\
\hline
\end{tabular}

Entre 1822 y 1833 , el $80 \%$ del dinero ingresado en las arcas de la V.O.T. procedía de las cuotas de sus hermanos. La práctica inexistencia de patrimonio raíz propiciaba la necesidad de tener que ser extremadamente rígidos en la percepción de las limosnas para evitar el colapso de su hacienda. Esto no quiere decir que la fraternidad no se comportase con caridad franciscana con aquellos hermanos que por los avatares del destino, habían caído en la pobreza: normalmente, habiendo causa justificada, se concedía la exención. Además, la junta de gobierno permitía a algunos de los miembros de la fraternidad suplir sus obligaciones económicas con algún tipo de trabajo que pudiese resultar útil. Así acontecía con los criados pero también con los músicos de la catedral a los que se les condonaban sus obligaciones pecuniarias a cambio de su participación en las funciones religiosas. Otra fuente de ingresos eran los censos, recurso muy empleado por muchas cofradías y fraternidades de la V.O.T. en toda la Corona de Castilla. Sin embargo, en la de León su peso era casi anecdótico, muestra palpable de la debilidad de su economía. Más importantes eran los ingresos propiciados por limosnas individuales o colectivas. En este campo se pueden apreciar dos tipologías bien definidas: las limosnas ofrecidas por los sectores principales de la fraternidad, bien en una ocasión especial bien en las disposiciones testamentarias, y la recaudación de la saca de los viernes, destinada a mantener la lámpara del Santísimo de la capilla. En cuanto a las primeras, lo cierto es que los miembros de las clases pudientes no destacaron por su generosidad en sus testamentos; muestra de ello es la escasez del patrimonio raíz de la fraternidad. Sí se mostraban más receptivos en momentos de especial necesidad, sobre todo cuando era necesaria la realización de una obra en la capilla o la celebración de un acto extraordinario. En esas ocasiones, eran estos sectores los que lideraban la contribución económica que hacía frente al gasto extraordinario. De la misma manera, al menos en la primera mitad del siglo XIX, existía la costumbre de que los ministros salientes, tanto hombres como mujeres, donaran a la fraternidad cierta cantidad de dinero ${ }^{72}$. En resumen, la inexistencia de un mínimo patrimonio raíz y la escasa generosidad de las elites, propiciaron una

${ }^{72}$ En $1824 \mathrm{D}^{\mathrm{a}}$. Josefa García Sánchez, una vez concluido su mandato como ministra de la V.O.T. dio en limosna a la fraternidad 160 reales. En 1831, la ministra saliente $\mathrm{D}^{\mathrm{a}}$. Gabriela Fernández y su viceministra ofrecen otra limosna de 100 reales, lo mismo que su sucesora $\mathrm{D}^{\mathrm{a}}$. Escolástica Ferreras un año después. A.V.O.T.L., Libro de cuentas (1822-1833), fols. 7, 47 y ss. 
más que evidente debilidad de la economía terciaria que, dada su dependencia de las contribuciones de los hermanos, se resintió notablemente en las críticas primeras décadas del siglo XIX. En cuanto a los gastos, observamos como la V.O.T. leonesa se orientaba fundamentalmente a su dimensión devocional y funeraria, aparcando su labor asistencial:

\begin{tabular}{l|r|r}
\hline \multicolumn{1}{c|}{ Gastos } & Total & $\%$ \\
\hline Celebraciones religiosas & 8.600 & 39,8 \\
Criados & 5.966 & 27,6 \\
Comunidad franciscana & 4.476 & 20,7 \\
Padre visitador & 2.402 & 11,1 \\
Limosnas & 138 & 0,6 \\
\hline TOTAL & 21.582 & 100,0 \\
\hline
\end{tabular}

Las limosnas a hermanos pobres durante la década de los veinte del siglo XIX no llegaban siquiera al $1 \%$ del conjunto total de gastos. Se trata en la mayoría de los casos de gratificaciones a peregrinos aunque también, de vez en cuando, aparecen otros donativos, como los 30 reales aprobados por el discretorio en marzo de 1827 para la casa santa de Jerusalen ${ }^{73}$. Más importante eran los gastos generados por el personal de servicio con que contaba la fraternidad: a finales del Antiguo Régimen, el hermano sacristán cobraba 400 reales al año, amén de correr la tercera orden con los gastos de vestido y calzado. También recibían ese extra los hermanos de caridad que se encargaban de conducir los féretros al lugar de enterramiento. Estos gastos de personal suponían en el XIX casi el 28\% del total, aún a pesar de la reducción de hermanos sirvientes con respecto al siglo anterior. Pero, sin duda alguna, el capítulo de gastos más importante lo generaban las ceremonias religiosas, en donde incluimos las funciones generales y particulares por los hermanos difuntos. Aproximadamente el $70 \%$ del dinero de las arcas terciarias se dirigía a tal fin, pues las partidas destinadas a los estipendios del padre visitador y la comunidad franciscana estaban estrechamente vinculadas a esa dimensión religiosa.

En resumen, si desde el punto de vista social, la V.O.T. contaba con un importante arraigo dentro de las capas acomodadas, desde el económico, esa presencia no benefició excesivamente a sus arcas, al menos si tenemos en cuenta

73 A.V.O.T.L., Libro de cuentas (1822-1833), fol. 37 vto. 